\title{
Uso de reguladores vegetais na propagação via estaquia de umbu-cajazeira
}

\section{Use of plant regulators in the propagation via cutting of umbu-cajazeira}

\author{
Mário L. M. Véras1,*, Raimundo Andrade², Lucimara F. de Figueredo³, Vandeilson L. Araujo³,

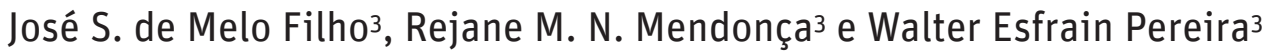 \\ ${ }^{1}$ Universidade Federal de Viçosa - Campus Viçosa, Doutorado em Fitotecnia, Campus Universitário, CEP: 36570 900, Viçosa-MG, Brasil \\ 2 Universidade Estadual da Paraíba - Campus IV, Centro de Ciências Humanas e Agrárias, Sitio Cajueiro, Catolé do Rocha-PB, Brasil \\ 3 Universidade Federal da Paraiba - Centro de Ciências Agrárias - Campus II Doutorado em Agronomia, Rodovia PB 079 - Km 12, Caixa Postal 66, CEP 58397-000, Areia-PB, Brasil \\ (*E-mail: mario.deus1992@bol.com.br) \\ http://dx.doi.org/10.19084/RCA17153
}

Recebido/received: 2017.06 .23

Recebido em versão revista/received in revised form: 2018.01.19

Aceite/accepted: 2018.03.14

\section{R E S U M O}

A umbu-cajazeira é uma das frutíferas nativas mais exploradas na região semiárida brasileira, já que seus frutos são bastante procurados. Neste sentido, objetivou-se avaliar o tratamento de planta matriz com zinco e enraizamento de estacas de umbu-cajazeira. O experimento foi conduzido sob delineamento inteiramente casualizado, com nove tratamentos, com níveis pré-determinados pela matriz “Composto Central de Box" referente às doses de zinco (0; 5,8; 30; 34,2 e $\left.40 \mathrm{mg} \mathrm{L}^{-1}\right)$ e combinações com as doses de AIB (0; 872,35; 3000; 5127,65 e $\left.6000 \mathrm{mg} \mathrm{L}^{-1}\right)$, e quatro repetições. O tratamento de plantas matrizes com zinco não afetou o percentual de estacas brotadas, número, comprimento e diâmetro de brotações, o enraizamento e a produção de massa seca de estacas de umbu-cajazeira; O ácido indolbutírico promove o enraizamento de estacas de umbu-cajazeira, sendo que, a concentração máxima de $6000 \mathrm{mg} \mathrm{L}^{-1}$ de AIB proporciona os maiores percentuais de enraizamento adventício, com 43,75\% de estacas enraizadas.

Palavras-chave: Spondias spp., enraizamento, zinco, fitohormônio.

\section{A B S T R A C T}

The umbu-cajazeira is one of the most exploited native fruits in the Brazilian semi-arid region, since its fruits are highly sought after. In this sense, the objective was to evaluate the treatment of stock plants with zinc and rooting of umbucajazeira cuttings. The experimental design was completely randomized, with four replications. The experiment was conducted in a completely randomized design, with nine treatments, with levels determined by the matrix "Central Box Compound" for the doses of zinc $\left(0 ; 5.8 ; 30 ; 34.2\right.$ and $\left.40 \mathrm{mg} \mathrm{L}^{-1}\right)$ and combinations with AIB doses $(0 ; 872,35 ; 3.000$; $5.127,65$ and $\left.6000 \mathrm{mg} \mathrm{L}^{-1}\right)$, and four replicates. Treatment of stock plants with zinc did not affect the percentage of cuttings sprouts, number, length and diameter of shoots, rooting and dry mass production of umbu-cajazeira cuttings; Indolbutyric acid directly influences the rooting of umbu-cajazeira cuttings, and the maximum concentration of 6000 $\mathrm{mg} \mathrm{L}^{-1}$ of IBA provides the highest percentages of adventitious rooting, with $43.75 \%$ of rooted cuttings.

Keywords: Spondias spp., rooting, zinc, phytohormone.

\section{INTRODUÇÃO}

A umbu-cajazeira (Spondias sp.) é uma planta nativa brasileira da família das Anacardiáceas e possui características muito semelhantes as outras plantas do gênero Spondias. É de grande relevância socioeconômica, pois a madeira é utilizada para produção de celulose e os frutos apresentam grande potencial de utilização para fabricação de polpa, sorvetes, doces ou serem consumidos in natura. Contudo, devido à falta de informações relacionadas à propagação, adubação e cultivo, a espécie é explorada de forma extrativista, no qual os agricultores coletam os frutos de plantas oriundas de áreas naturais e quintais e os vende 
em feiras livres (Santos et al., 2013; Viana et al., 2015).

Uma das etapas mais importantes no cultivo comercial de frutíferas é a fase de mudas, uma vez que mudas de boa qualidade originam pomares bem formados. Sendo assim, a escolha de um método de propagação de uma planta é essencial. Dentre os métodos de propagação adotados para a umbu-cajazeira a estaquia é um dos mais adequados; contudo, a estaquia depende principalmente da capacidade de formação de raízes de cada espécie e/ou cultivar, além disso, a qualidade do sistema radicular formado e o desenvolvimento posterior da área de produção é um fator relevante na propagação via estaquia (Emer et al., 2016).

Como forma de estimular o enraizamento adventício, tem-se utilizado reguladores vegetais sintéticos pertencentes ao grupo auxinas, dentre eles o ácido indolbutírico. Os indutores vegetais induzem o processo de enraizamento em espécies de difícil enraizamento, como é o caso das Spondias; além disso, atuam reduzindo o tempo da formação de raízes e de permanência de estacas no leito de enraizamento (Zem et al., 2015).

Na literatura poucos trabalhos têm evidenciado um bom percentual de enraizamento de umbu-cajazeira e de outras Spondias. Tosta et al. (2012) em estacas de umbu-cajazeira observaram $95 \%$ de estacas enraizadas sob aplicação de $3000 \mathrm{mg} \mathrm{L}^{-1}$ de AIB. Rios et al. (2012), verificaram que a maior percentagem de enraizamento em estacas de umbuzeiro ocorreu na concentração de $6000 \mathrm{mg} \mathrm{L}^{-1}$ de AIB, observando um percentual de 9,34\%. No entanto,Paula et al. (2007) em estacas de umbuzeiro, constataram percentual de $33,3 \%$ de estacas enraizadas, com a aplicação de $500 \mathrm{mg} \mathrm{L}^{-1}$ de AIB.

Outros fatores influenciam o enraizamento, dentre eles o estado nutricional da planta matriz, uma vez que no processo de rizogênese adventícia alguns elementos minerais são essenciais para a síntese de auxina, contudo, a nutrição mineral e o enraizamento adventício apresentam uma complexidade já que a formação de raízes em estacas inclui múltiplas fases. Outrossim, há poucos estudos envolvendo a nutrição mineral e a rizogênese. Dentre os elementos minerais importantes para o enraizamento, o zinco é essencial, visto que participa da rota do triptofano, aminoácido precursor da auxina. Apesar disso há poucos estudos com o uso de zinco como cofator importante no enraizamento, podendo até mesmo substituir a utilização de auxinas sintéticas (Nicoloso et al., 1999).

Alguns trabalhos apontam que a aplicação de zinco nas plantas matrizes antes da coleta das estacas pode aumentar o percentual de enraizamento; no entanto, em Spondias não há trabalhos evidenciando o efeito do tratamento de planta matriz. Em outras espécies como florestais (Platanus acerifolia Ait.), Nicoloso et al. (1999) apontam que não houve efeito do zinco no enraizamento de estacas.

As condições das plantas matrizes influenciam diretamente sobre o enraizamento de estacas. Em Spondias, e especificamente para a umbu-cajazeira a falta de conhecimento sobre o efeito de tratamentos de plantas matrizes tem acarretado a obtenção de baixos percentuais de enraizamento. Neste sentido, objetivou-se avaliar o efeito do tratamento na planta matriz com zinco sobre o enraizamento de estacas de umbu-cajazeira tratadas com ácido indolbutírico.

\section{MATERIAL E MÉTODOS}

O experimento foi conduzido no período de maio a agosto de 2016 no viveiro de Fruticultura, pertencente à Universidade Federal da Paraíba no município de Areia-PB, Brasil, situada nas coordenadas geográficas $6^{\circ} 51^{\prime} 47^{\prime \prime}$ e $7^{\circ} 02^{\prime} 04^{\prime \prime}$ latitude Sul e longi-

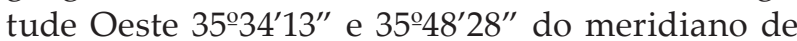
Greenwich. Foram selecionados ramos lenhosos de plantas de umbu-cajazeira (Spondias sp.), provenientes do município de Catolé do Rocha - PB, Brasil. As plantas matrizes de umbu-cajazeira foram obtidas por estaquia com idade variando entre 10 a 20 anos.

O delineamento experimental utilizado foi inteiramente casualizado, com quatro repetições; os tratamentos consistiram de cinco doses de AIB e de cinco doses de $\mathrm{Zn}$, totalizando nove combinações geradas através da matriz Composto Central de Box (Mateus et al., 2001), em que a parcela experimental consistiu de doze estacas de umbu-cajazeira. Por se tratar de um experimento que envolve uma grande quantidade de unidades experimentais, o 
Composto Central de Box foi a melhor alternativa para o presente experimento.

As combinações de AIB e $\mathrm{Zn}$, respectivamente, em mg L-1: T1 - 872,35 e 5,8; T2 - 872,35 e 20; T3 $-5127,65$ e 5,$8 ; \mathrm{T} 4-5127,65$ e 20; T5 - 3000 e 40; T6 3000 e $0 ; \mathrm{T} 7-6000$ e 34,2; T8 - 0 e 34,2; e T9 - 3000 e 34,2. As doses máximas de AIB $\left(6000 \mathrm{mg} \mathrm{L}^{-1}\right)$ e $\mathrm{Zn}\left(40 \mathrm{mg} \mathrm{L}^{-1}\right)$.

O tratamento com zinco foi feito com o produto comercial maxizinco ${ }^{\circledR}$, aplicado via pulverização nas plantas matrizes 7 dias antes da retirada dos ramos. As doses de zinco correspondentes aos tratamentos foram diluídas conforme a indicação comercial do produto de $1000 \mathrm{~g}_{\text {de zinco L }}^{-1}$, encontrando-se a partir da mesma a dose específica para cada tratamento. O zinco foi diluído dentro de um pulverizador costal e aplicado na copa das plantas de umbuzeiro com volume aproximado de $4 \mathrm{~L} /$ planta.

Sete dias após a aplicação do zinco, foram coletados ramos de umbu-cajazeira com 3 a $4 \mathrm{~mm}$ de diâmetro e aproximadamente $30 \mathrm{~cm}$ de comprimento, sendo acondicionados em papel umedecido, colocados em sacos plásticos e transportados para o Viveiro de Fruticultura na Universidade Federal da Paraíba, município de Areia-PB. Estes foram levadas para a câmara de nebulização onde foi realizado o corte das estacas, sendo a parte superior cortada reta e a basal cortada em bisel, ficando com $20 \mathrm{~cm}$ de comprimento.

A solução hidroalcoólica do AIB foi preparada pela pesagem de $872,35 \mathrm{mg} \mathrm{L}^{-1}$ de AIB e dissolvidos em $50 \mathrm{~mL}$ de álcool 96\%, em um copo de precipitação. Após totalmente dissolvido, completou-se o volume para $1000 \mathrm{~mL}$, com água destilada, obtendo-se então a concentração de $872,35 \mathrm{mg} \mathrm{L}^{-1}$ de AIB; sendo repetido esse mesmo procedimento para as demais doses utilizadas.

Após o término do preparo, as estacas foram agrupadas, por repetição e tiveram $1,0 \mathrm{~cm}$ da base colocada na solução hormonal por 5 segundos, conforme o tratamento. Posteriormente, realizou-se o plantio em tubetes com diâmetro interno de $26 \mathrm{~mm}$ e diâmetro externo de $33 \mathrm{~mm}$ e volume de $55 \mathrm{~cm}^{3}$, preenchidos com substrato formado de areia e composto orgânico, na proporção 1:1 (v/v); sendo colocados sob sombrite a $50 \%$ de luz e em estufa sob nebulização, com abertura de 10 segundos e intervalos de 15 minutos.

Aos 90 dias após a instalação do experimento foram avaliados: o percentual de estacas brotadas, o comprimento das brotações, o diâmetro das brotações, o percentual de estacas enraizadas, o percentual de estacas vivas com e sem calo, o percentual de estacas mortas, o número de raízes por estaca, o comprimento da raiz, a massa seca das raízes, folha e a massa seca total.

Os dados foram submetidos à análise de variância pelo teste F. Para as variáveis com efeito da interação significativa foram ajustadas a superfície de resposta, e caso contrário foi feito a análise de regressão polinomial para os fatores isolados (AIB e Zn). Quando não houve efeito significativo dos fatores isolados utilizou-se o teste de Dunnett a 5\% de significância para comparar as doses máximas de cada fator com as demais doses. As análises foram realizadas com o software estatístico SAS ${ }^{\circledR}$ (Cody, 2015).

\section{RESULTADOS E DISCUSSÃO}

O resumo da análise de variância com os respectivos valores de $\mathrm{F}$ para as variáveis avaliadas consta do Quadro 1. A interação AIB x zinco bem como o fator isolado zinco não influenciaram as variáveis analisadas. O percentual de estacas brotadas (EB), o comprimento das brotações (CB), o diâmetro das brotações (DB), percentual de estacas enraizadas (EE), percentual de estacas mortas (EM) e número de raízes por estaca (NR) foram influenciadas pelas doses de AIB a nível de $1 \%$ de significância.

O aumento das doses de AIB influenciou o percentual de estacas brotadas, o número, no comprimento e diâmetro de brotações de estacas de umbu-cajazeira, sendo que as doses estimadas de 3250 e $2500 \mathrm{mg} \mathrm{L}^{-1}$ proporcionaram menor comprimento e diâmetro de brotações, que foi de $2,50 \mathrm{~cm}$ (Figura 1A) e 1,39 mm (Figura 1B), respectivamente. Os maiores valores para o percentual de estacas brotadas, número, comprimento e diâmetro de brotações ocorreram nas doses de $0 \mathrm{mg} \mathrm{L}^{-1}$ de AIB, apresentando os valores de 72,91\% (Figura 1A), 1,5 brotações (Figura 1B), 4,09 cm (Figura 1C) e 2,48 mm (Figura 1D), respectivamente. 
Quadro 1 - Resumo de análise de variância para o percentual de estacas brotadas (EB), o comprimento das brotações (CB), o diâmetro das brotações (DB), o percentual de estacas enraizadas (EE), o percentual de estacas vivas Com (EVC) e sem calo (EVSC), o percentual de estacas mortas (EM), o número de raízes por estaca (NR), o comprimento da raiz (CR), a massa seca das raízes (MSR), folha (MSF) e a massa seca total (MST) de estacas de umbu-cajazeira em função da aplicação de AIB (A) e zinco em planta matrizes (Z)

\begin{tabular}{|c|c|c|c|c|c|c|c|}
\hline Fontes de variação & GL & & & Arado & Médio & & \\
\hline & & EB & CВ & DB & EE & EVC & EVSC \\
\hline $\mathrm{AIB}(\mathrm{A})$ & 4 & $641,21^{* *}$ & $7,02^{* *}$ & $5,38^{* *}$ & $272,89^{* *}$ & $487,69^{\mathrm{ns}}$ & $0,96^{\mathrm{ns}}$ \\
\hline Zinco $(Z)$ & 4 & $1668,49^{\mathrm{ns}}$ & $7,04^{\mathrm{ns}}$ & $4,72^{\mathrm{ns}}$ & $783,72^{\text {ns }}$ & $435,58^{\mathrm{ns}}$ & $0,98^{\mathrm{ns}}$ \\
\hline$A \times Z$ & 8 & $641,21^{\mathrm{ns}}$ & $7,02^{\mathrm{ns}}$ & $5,38^{\mathrm{ns}}$ & $272,89^{n s}$ & $487,69^{\mathrm{ns}}$ & $0,95^{\mathrm{ns}}$ \\
\hline Resíduo & 27 & 57,22 & 0,06 & 0,02 & 17,37 & 55,94 & 15,45 \\
\hline Média & - & 50,23 & 3,33 & 2,17 & 19,21 & 31,71 & 10,18 \\
\hline \multirow[t]{2}{*}{ CV (\%) } & - & 15,06 & 7,55 & 7,50 & 21,70 & 23,59 & 28,61 \\
\hline & & EM & NR & CR & MSR & MSF & MST \\
\hline $\operatorname{AIB}(\mathrm{A})$ & 4 & $1286,23^{* *}$ & $2,18^{* *}$ & $7,91^{* *}$ & $11,29^{\text {ns }}$ & $16,52^{\text {ns }}$ & $55,16^{\text {ns }}$ \\
\hline Zinco (Z) & 4 & $687,41^{\mathrm{ns}}$ & $0,81^{\mathrm{ns}}$ & $7,13^{\mathrm{ns}}$ & $4,27^{\mathrm{ns}}$ & $6,26^{\text {ns }}$ & $20,91^{\text {ns }}$ \\
\hline$A \times Z$ & 8 & $1286,23^{\mathrm{ns}}$ & $2,18^{\mathrm{ns}}$ & $7,91^{\mathrm{ns}}$ & $11,29^{\mathrm{ns}}$ & $16,52^{\text {ns }}$ & $55,16^{\text {ns }}$ \\
\hline Resíduo & 27 & 55,30 & 0,41 & 0,05 & 0,15 & 0,23 & 0,77 \\
\hline Média & - & 22,22 & 1,58 & 3,41 & 3,96 & 4,78 & 8,76 \\
\hline CV (\%) & - & 18,05 & 20,77 & 6,76 & 10,02 & 10,03 & 10,02 \\
\hline
\end{tabular}

CV: coeficiente de variação; ns, **, * respectivamente não significativos, significativo a $p<0,01$ e $p<0,05$.

Os valores supracitados estão menores que os observados Tosta et al. (2012) em estacas de umbu-cajazeira, que constataram um aumento no número de brotações à medida que se aumentou a concentração de AIB, (em média, até $3500 \mathrm{mg} \mathrm{L}^{-1}$ ), e a partir desta concentração houve um decréscimo, obtendo valor máximo de 2,9 brotações por estaca. Semelhantemente, Gomes et al. (2005) estudando a influência do AIB sobre o número de brotações de estacas e o diâmetro das brotações de umbu-cajazeira (Spondias spp.) verificaram que o uso do AIB proporcionou aumento significativo quanto a estas variáveis.

Em relação ao comprimento de brotações, os resultados supracitados corroboram com os apresentados por Tosta et al. (2012) que constataram um aumento no comprimento das brotações de cajaraneira, à medida que se aumentou a concentração de AIB; no entanto obtiveram maior comprimento que o apresentado no presente ensaio, com valor máximo de $5,6 \mathrm{~cm}$ na concentração de $3.045 \mathrm{mg} \mathrm{L}^{-1}$ de AIB. Gomes et al. (2005) também verificaram que a utilização de AIB aumentou o comprimento das brotações em estacas de umbu-cajazeira.

Um dos aspectos negativos da formação de brotações é a redução que pode ocasionar no enraizamento, quando as reservas da estaca são utilizadas para este fim, em detrimento do enraizamento. Porém, quando há tempo suficiente para que estas possam produzir auxinas e enviar para a base da estaca, num movimento basípeto, podem favorecer o enraizamento.

As doses de AIB, aumentaram o percentual de estacas enraizadas e estacas mortas, tendo como ponto mínimo sob as doses de 1000 (Figura 2A) e $3575 \mathrm{mg} \mathrm{L}^{-1}$ (Figura 2B), correspondendo aos percentuais de 10,41 e 18,31\%, respectivamente. Verifica-se ainda que os maiores percentuais de estacas enraizadas foram obtidos na concentração máxima de AIB (6000 $\mathrm{mg} \mathrm{L}^{-1}$ ), apresentando 43,75\% de enraizamento (Figura 2A). Para o percentual de estacas mortas (Figura 2B), observou-se que o incremento nas doses de AIB diminuiu a sobrevivência das estacas de umbu-cajazeira, em que os maiores percentuais de estacas vivas foram observados nas estacas sem tratamento com AIB $\left(0 \mathrm{mg} \mathrm{L}^{-1}\right)$.

Os reguladores vegetais são usados para induzir o enraizamento de forma quantitativa e qualitativa. Os fatores que influenciam o enraizamento são divididos em endógenos, como juvenilidade, reservas nutricionais e hormonais e exógenos, tais como umidade do ar, temperatura, luminosidade e a disponibilidade hídrica (Botin e Carvalho, 2015). 
Na propagação vegetativa, o teor de auxina endógena deve ser levado em consideração, já que as plantas apresentam um conteúdo endógeno de auxina, sendo assim, no intuito de estimular o enraizamento são utilizados reguladores vegetais, como o ácido indolbutírico (Peña et al., 2012).

Alguns trabalhos têm mostrado que para que o enraizamento e a formação de calos ocorram, outros fatores devem ser considerados, tais como: tamanho das estacas, tipo de luz, substrato e condições de umidade do ar na casa de vegetação. Em contrapartida, a presença de calos nas estacas pode ser um indicativo de que o material vegetativo tem baixa juvenilidade (Wendling et al., 2014).
Em estacas de cajazeira, Véras et al. (2017) constataram que os maiores percentuais de enraizamento de estacas foram observadas sem a aplicação de ethephon na planta mãe e com o uso de $3.000 \mathrm{mg} \mathrm{L}^{-1}$ de AIB, obtendo-se $31,94 \%$ de estacas enraizadas. No presente trabalho os resultados obtidos foram superiores.

Em outras frutíferas, Yamamoto et al. (2013) não verificaram diferença significativa para o percentual de estacas enraizadas quando as estacas de amoreira preta Xavante foram tratadas com AIB. Nacata et al. (2014), em estacas de caramboleira, constataram que a porcentagem enraizamento, de calejamento e de sobrevivência, apresentaram
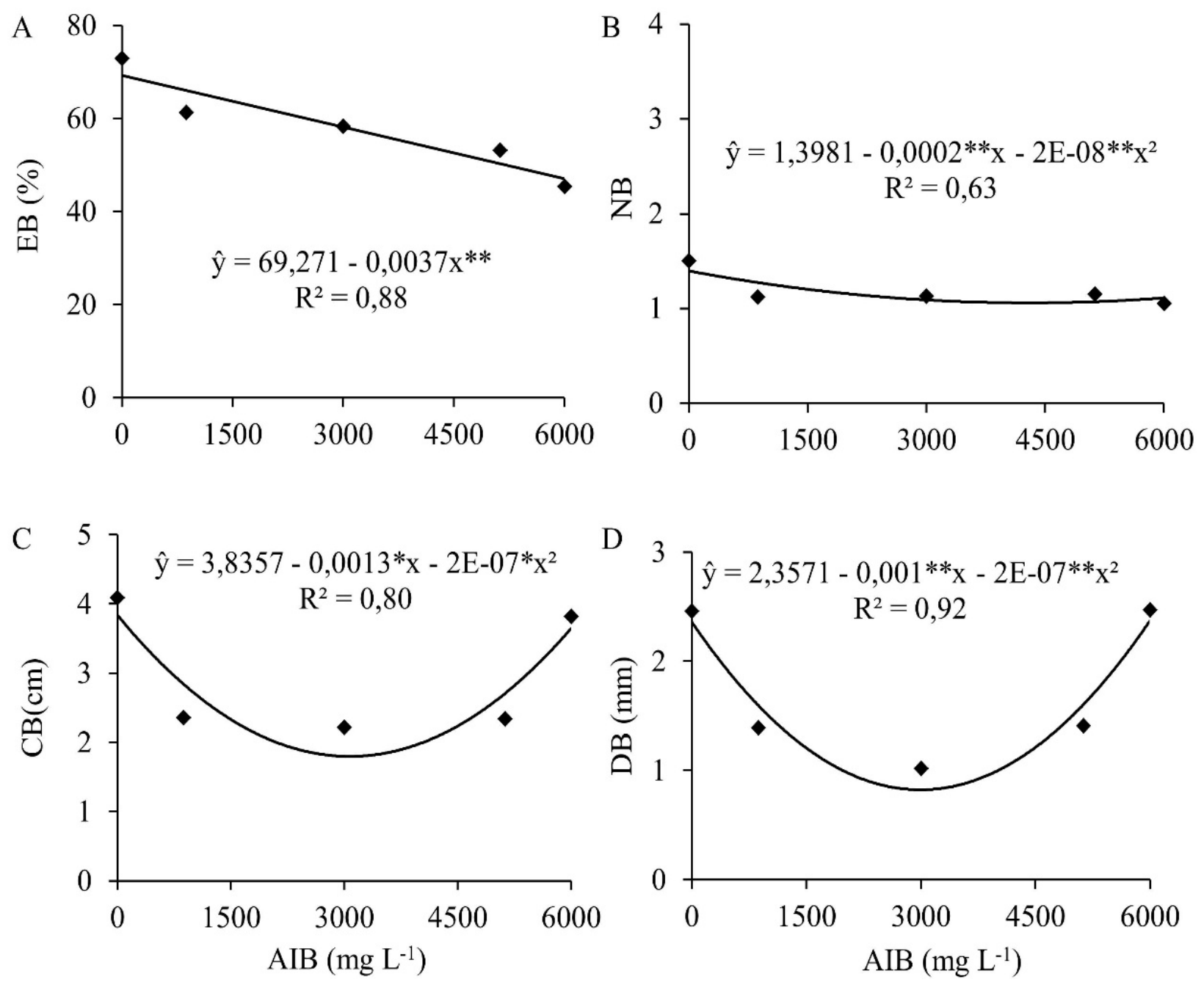

Figura 1 - Doses de ácido indolbutírico sobre o percentual de estacas brotadas (A), número de brotações (B), comprimento de brotações (C) e diâmetro de brotações (D) de estacas de umbu-cajazeira. 

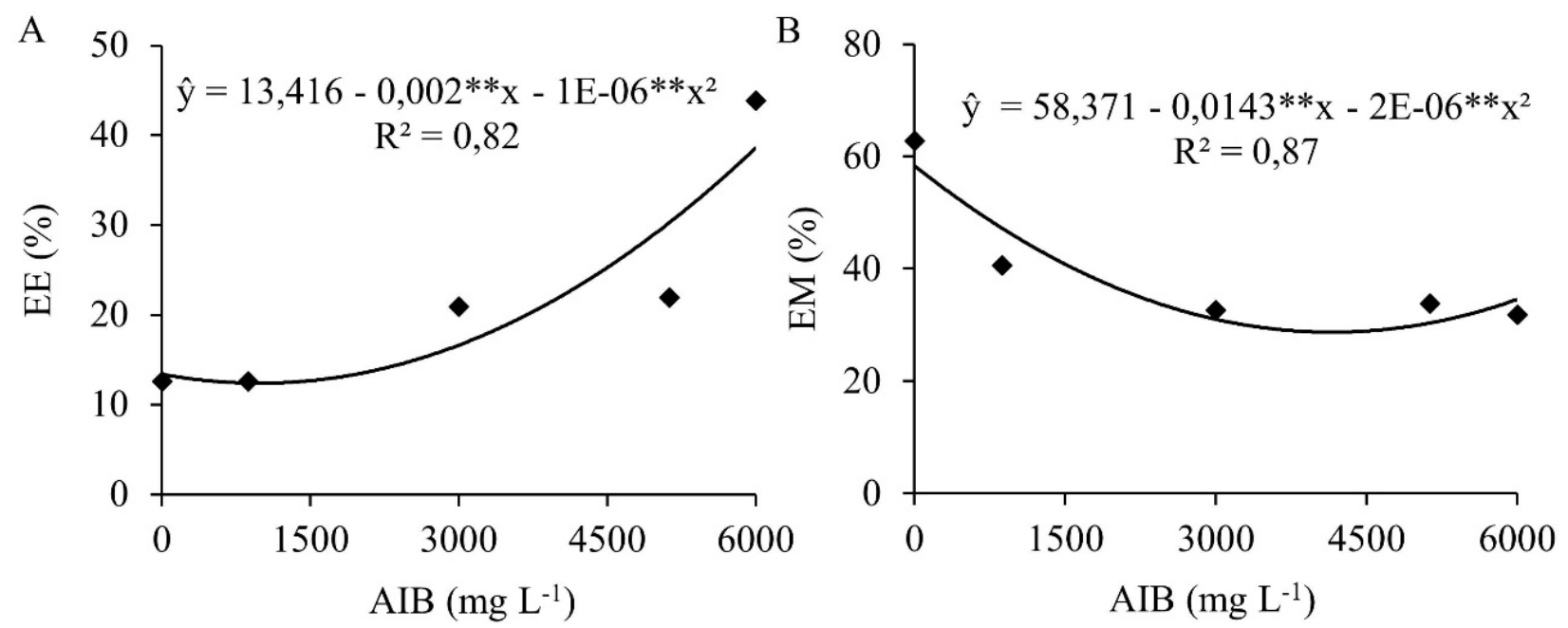

Figura 2 - Doses de ácido indolbutírico sobre o percentual de estacas enraizadas (A) e estacas mortas (B) de umbu-cajazeira.

diferença significativa, na qual a concentração de $100 \mathrm{mg} \mathrm{L}^{-1}$ de AIB apresentou os melhores resultados para estas variáveis.

Sabião et al. (2011), em maracujazeiro-doce (Passiflora nitida) observaram que a porcentagem de sobrevivência de estacas não diferiram quando foi aplicado o AIB, contudo, a concentração máxima (5000 $\mathrm{mg} \mathrm{L}^{-1}$ ) apresentou valores superiores $(87,69 \%$ de sobrevivência). Enquanto que para a porcentagem de enraizamento constataram que houve diferença significativa, obtendo $87,69 \%$ de enraizamento na concentração de $5000 \mathrm{mg} \mathrm{L}^{-1}$. Para o percentual de estacas sobreviventes, Paula et al. (2007), observaram que estacas lenhosas de umbuzeiro sem tratamento com AIB apresentaram o maior percentual de sobrevivência $(69,44 \%)$.

Para o comprimento da raiz, observou-se que as doses de AIB influenciaram, atingindo o ponto de mínimo $(0,99 \mathrm{~cm})$ com a dose de $2333 \mathrm{mg} \mathrm{L}^{-1}$. Com o aumento posterior o maior comprimento de raiz foi obtido nas estacas tratadas com a concentração de $6000 \mathrm{mg} \mathrm{L}^{-1}$ de AIB (Figura 3).

Tais resultados positivos são indicativos da eficiência do AIB para o incremento no volume e comprimento de raízes, sendo assim, o tratamento com AIB proporciona às estacas condições de enraizarem e formar estacas de alta qualidade, uma vez que, para o estabelecimento das mudas em campo bem como o desenvolvimento adequado das plantas é preciso que o sistema radicular seja de boa qualidade (Silva et al., 2012). Além disso, embora não aumente o percentual de enraizamento, o AIB induz a formação de primórdios radiculares em virtude de acelerar o metabolismo da planta.

Uma das vantagens do efeito da auxina é a promoção de enraizamento, consequentemente, um bom sistema radicular proporciona maior capacidade de absorção de água e nutrientes pela planta, contribuindo para a rápida alocação de substâncias para a planta (Dourado Neto et al., 2014).

Rios et al. (2012), constataram que o maior número de raízes por estacas de umbuzeiro ocorreu na concentração de $6000 \mathrm{mg} \mathrm{L}^{-1}$. Tosta et al. (2012), também observaram que o maior número de raízes por estacas teve um incremento com o aumento das

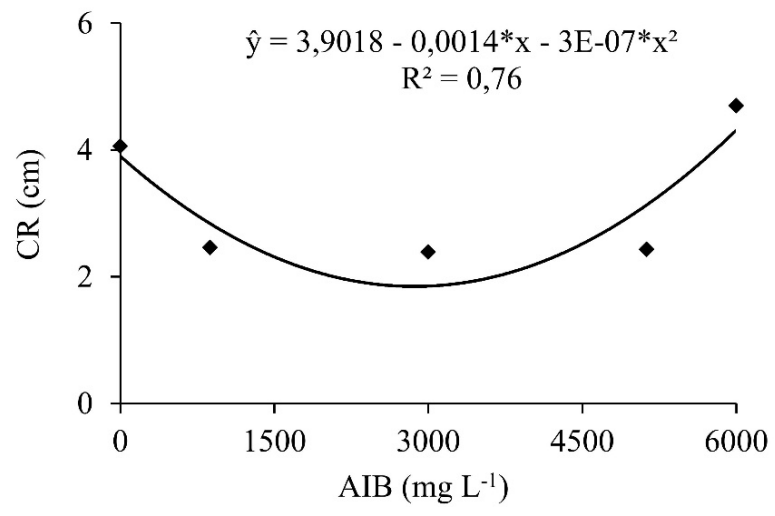

Figura 3 - Doses de ácido indolbutírico sobre o comprimento da raiz de estacas de umbu-cajazeira. 
doses de $\mathrm{AIB}$, observando-se que o maior número de raízes estimado por estacas de umbu-cajazeira (3,8 unidades estaca) ocorreu na concentração máxima de $8545 \mathrm{mg} \mathrm{L}^{-1}$ de AIB.

Apesar de não ter apresentado diferença significativa, ao aplicar o teste de Dunnet a 5\%, observa-se no Quadro 2 que houve diferenças significativas entre os tratamentos de $6000 \mathrm{mg} \mathrm{L}^{-1}$ de AIB e de 40 $\mathrm{mg} \mathrm{L}^{-1}$ de zinco e as demais doses de AIB e Zn.

O tratamento com zinco em plantas matrizes de umbu-cajazeira não influenciou o percentual de estacas brotadas, o número, o comprimento e diâmetro de brotações, apresentando os valores médios de $50,23 \%, 1,18,3,33 \mathrm{~cm}$ e $2,17 \mathrm{~mm}$, respectivamente (Quadro 1). Embora não tenha apresentado diferença significativa, ao aplicar o teste de Dunnet para o percentual de estacas brotadas, número de brotações, comprimento e diâmetro de brotações, observou-se a dose máxima de $\mathrm{Zn}$ diferiu das demais doses apresentando os valores de $66,67 \%$; 4,2 brotações; $4 \mathrm{~cm}$ e $3,33 \mathrm{~mm}$, respectivamente (Quadro 2).

Igualmente às brotações, o percentual de estacas enraizadas, estacas vivas com calo, estacas vivas sem calo e estacas mortas não apresentaram diferença significativa para a interação zinco x AIB nem para o tratamento isolado com zinco, apresentando os valores médios $19,21 \%, 31,71 \%, 10,18 \%$ e $22,22 \%$, respectivamente (Quadro 1). Enquanto que para as doses de AIB, o percentual de estacas vivas com calo e sem calo não foram influenciadas estatisticamente, apresentando os percentuais médios de $31,71 \%$ e $10,18 \%$, respectivamente. Apesar de não ter apresentado diferença significativa, ao aplicar o teste de Dunnet para o percentual de estacas enraizadas, percentual de estacas vivas com calo, estacas vivas sem calo e percentual de estacas mortas, comparando a maior dose com as demais, observou-se as doses máximas de AIB e Zn diferiram dos tratamentos controles apresentando os percentuais de $43,75 \% ; 30 \% ; 9,72 \%$ e $41,66 \%$ para AIB e $27,08 \% ; 31,22 \% ; 11,02 \%$ e $20,83 \%$ para $Z n$, respectivamente (Quadro 2).

O número e comprimento de raiz também não apresentaram diferença em função das doses de zinco, com valores médios de 1,58 g e 3,41 cm, respectivamente. Ao aplicar o teste de Dunnet para o comprimento e número de raiz comparando a dose máxima com as demais doses, observou-se as doses máximas de AIB e Zn não diferiram das demais (Quadro 2).

Quadro 2 - Comparação das doses máximas de $6000 \mathrm{mg} \mathrm{L}^{-1}$ de AIB e de $40 \mathrm{mg} \mathrm{L}^{-1}$ de zinco pelo teste de Dunnet com as demais doses para o percentual de estacas brotadas (EB), o comprimento das brotações (CB), o diâmetro das brotações (DB), 0 percentual de estacas enraizadas (EE), 0 percentual de estacas vivas com (EVC) e sem calo (EVSC), o percentual de estacas mortas (EM), o número de raízes por estaca (NR), o comprimento da raiz (CR), a massa seca das raízes (MSR), folha (MSF) e a massa seca total (MST) de estacas de umbu-cajazeira em função da aplicação de AIB (A) e zinco em planta matrizes ( $Z$ )

\begin{tabular}{|c|c|c|c|c|c|}
\hline \multicolumn{6}{|c|}{ Tratamentos } \\
\hline \multirow[t]{2}{*}{ Variáveis } & \multicolumn{5}{|c|}{ Doses de AIB } \\
\hline & 0 & 872,35 & 3000 & 5127,65 & 6000 \\
\hline EB & $72,91^{*}$ & $31,25^{\mathrm{ns}}$ & $53,12^{*}$ & $58,33^{*}$ & 35,41 \\
\hline NB & $2,83^{*}$ & $1,25^{\mathrm{ns}}$ & $1,2^{\mathrm{ns}}$ & $1,25^{\mathrm{ns}}$ & 1,50 \\
\hline $\mathrm{CB}$ & $4,09^{\text {ns }}$ & $2,34^{*}$ & $2,36^{*}$ & $2,32^{*}$ & 3,92 \\
\hline DB & $2,46^{\mathrm{ns}}$ & $1,41^{*}$ & $1,49^{*}$ & $1,43^{*}$ & 2,47 \\
\hline EE & $12,50^{*}$ & $13,54^{*}$ & $20,83^{*}$ & $13,54^{*}$ & 43,75 \\
\hline EVC & $32,58^{\text {ns }}$ & $34,37^{\mathrm{ns}}$ & $32,80^{\mathrm{ns}}$ & $31,33^{\text {ns }}$ & 30,00 \\
\hline EVS & $10,41^{\text {ns }}$ & $10,4^{\mathrm{ns}}$ & $10,41^{\mathrm{ns}}$ & $10,41^{\mathrm{ns}}$ & 9,72 \\
\hline EM & $62,50^{*}$ & $40,62^{\mathrm{ns}}$ & $32,64^{*}$ & $43,75^{\mathrm{ns}}$ & 41,66 \\
\hline NR & $1,21^{\mathrm{ns}}$ & $1,24^{\mathrm{ns}}$ & $1,22^{\mathrm{ns}}$ & $1,20^{\mathrm{ns}}$ & 1,23 \\
\hline $\mathrm{CR}$ & $3,35^{\mathrm{ns}}$ & $3,43^{\mathrm{ns}}$ & $3,39 \mathrm{~ns}$ & $3,43^{\mathrm{ns}}$ & 3,42 \\
\hline MSR & $3,42^{\mathrm{ns}}$ & $3,51^{\mathrm{ns}}$ & $3,50^{\mathrm{ns}}$ & $3,55^{\text {ns }}$ & 3,51 \\
\hline MSF & $4,82^{\mathrm{ns}}$ & $4,75^{\mathrm{ns}}$ & $4,32^{\mathrm{ns}}$ & $4,63^{\mathrm{ns}}$ & 5,50 \\
\hline \multirow[t]{3}{*}{ MST } & $8,86^{\mathrm{ns}}$ & $8,53^{\mathrm{ns}}$ & $8,20^{\mathrm{ns}}$ & $8,21^{\mathrm{ns}}$ & 8,47 \\
\hline & \multicolumn{5}{|c|}{ Doses de Zn } \\
\hline & 0 & 5,8 & 20 & 34,2 & 40 \\
\hline EB & $48,33^{*}$ & $44,79^{*}$ & $49,58^{*}$ & $42,77^{*}$ & 66,67 \\
\hline NB & $3,50^{*}$ & $3,48^{*}$ & $3,23^{*}$ & $3,15^{*}$ & 4,20 \\
\hline CB & $3,03^{*}$ & $3,04^{*}$ & $3,00^{*}$ & $3,02^{*}$ & 4,00 \\
\hline DB & $2,46^{*}$ & $2,30^{*}$ & $2,20^{*}$ & $2,12^{*}$ & 3,33 \\
\hline EE & $21,08^{*}$ & $27,17^{\text {ns }}$ & $27,01^{\mathrm{ns}}$ & $27,08^{\mathrm{ns}}$ & 27,08 \\
\hline EVC & $28,00^{*}$ & $31,12^{\mathrm{ns}}$ & $31,23^{\mathrm{ns}}$ & $31,34^{\mathrm{ns}}$ & 31,22 \\
\hline EVS & $10,41^{\mathrm{ns}}$ & $10,41^{\mathrm{ns}}$ & $10,41^{\mathrm{ns}}$ & $10,41^{\mathrm{ns}}$ & 11,02 \\
\hline EM & $17,82^{*}$ & $21,83^{\mathrm{ns}}$ & $20,8^{\mathrm{ns}}$ & $22,82^{\mathrm{ns}}$ & 20,83 \\
\hline NR & $1,23^{\mathrm{ns}}$ & $1,2^{\mathrm{ns}}$ & $1,20^{\mathrm{ns}}$ & $1,23^{\mathrm{ns}}$ & 1,23 \\
\hline CR & $3,41^{\mathrm{ns}}$ & $3,41^{\mathrm{ns}}$ & $3,32^{\mathrm{ns}}$ & $3,00^{\mathrm{ns}}$ & 3,4 \\
\hline MSR & $3,48^{*}$ & $3,56^{*}$ & $3,58^{*}$ & $3,67^{*}$ & 4,46 \\
\hline MSF & $4,81^{*}$ & $4,78^{*}$ & $4,78^{*}$ & $4,67^{*}$ & 5,97 \\
\hline MST & $8,89^{*}$ & $8,86^{*}$ & $8,80^{*}$ & $8,95^{*}$ & 9,86 \\
\hline
\end{tabular}

* e ns: Contrastes significativos e não-significativos, respectivamente, pelo teste de Dunnett a $5 \%$. 
Alguns trabalhos apontam que a aplicação de zinco nas plantas matrizes antes da coleta das estacas pode aumentar o percentual de enraizamento, no entanto, em Spondias não há trabalhos evidenciando o efeito do tratamento de planta matriz. Em outras espécies como florestais (Platanus acerifolia Ait.), Nicoloso et al. (1999) apontam que não houve efeito do zinco no enraizamento de estacas, o que assemelha-se ao observado no presente trabalho.

A massa seca da raiz, folha e total também não apresentaram diferença significativa, quando relacionada às doses de $\mathrm{Zn}$ e $\mathrm{AIB}$, apresentando valores médios de 3,96 g para a massa seca da raiz, $4,78 \mathrm{~g}$ para a massa seca da folha e $8,76 \mathrm{~g}$ para a massa seca total. Apesar de não apresentar diferença significativa, ao aplicar o teste de Dunnett para a massa seca da raiz, folha e total, observou-se que apenas a dose máximas de $\mathrm{Zn}\left(40 \mathrm{mg} \mathrm{L}^{-1}\right)$ diferiram do tratamento controle, apresentando os valores de 4,46; 5,97 g e 9,86 g, respectivamente (Quadro 2).

O maior acúmulo de massa seca nas estacas pode ter ocorrido em virtude da rápida formação e desenvolvimento das raízes, em consequência disso, aumentando a absorção e translocação de fotoassimilados para parte aérea (Souza et al., 2015). Em estacas de umbu-cajazeira, Tosta et al. (2012) verificaram que o uso de AIB na concentração de $7775,9 \mathrm{mg} \mathrm{L}^{-1}$ proporcionou o maior acúmulo da massa seca do sistema radicular das estacas de umbu-cajazeira $\left(45,9 \mathrm{mg}\right.$ planta $\left.^{-1}\right)$. Resultados semelhantes foram obtidos por Peña et al. (2012), em que a dose de $8000 \mathrm{mg} \mathrm{L}^{-1}$ de AIB promoveu maior acúmulo de massa seca de raízes em estacas de mirtilo.

\section{CONCLUSÕES}

O tratamento de plantas matrizes com zinco não afetou o percentual de estacas brotadas, número de brotações, comprimento e diâmetro de brotações, o enraizamento e a produção de massa seca de estacas de umbu-cajazeira;

O ácido indolbutírico promove o enraizamento de estacas de umbu-cajazeira, sendo que, a concentração máxima de $6000 \mathrm{mg} \mathrm{L}^{-1}$ de AIB proporciona os maiores percentuais de enraizamento adventício, com $43,75 \%$ de estacas enraizadas.

\section{REFERÊNCIAS BIBLIOGRÁFICAS}

Botin, A.A. \& Carvalho, A. (2015) - Reguladores de crescimento na produção de mudas florestais. Revista de Ciências Agroambientais, vol. 13, n. 1, p. 83-96.

Cody, R. (2015) - An Introduction to SAS University Edition. Cary, NC. SAS Institute, 366 p.

Dourado Neto, D.; Dario, G.J.A.; Barbieri, A.P.P. \& Martin, T.N. (2014) - Ação de bioestimulante no desempenho agronômico de milho e feijão. Bioscience Journal, vol. 30, n. 3, p. 371-379.

Emer, A.A.; Schafer, G.; Avrella, E.D.; Delazeri, M.; Veit, P.A. \& Fior, C.S. (2016) - Influence of indolebutyric acid in the rooting of Campomanesia aurea semihardwood cuttings. Ornamental Horticulture, vol. 22, n. 1, p. 94-100.

Gomes, W.A.; Estrela, M.A.; Mendonça, R.M.N.; Silva, S.M.; Souza, A.P. \& Alves, R.E. (2005) - Enraizamento de estacas de umbu-cajazeira (Spondias spp.). Procedings of the Interamerican Society for Tropical Horticulture, vol. 47, n. 1, p. 231-233.

Mateus, N.B.; Barbin, D. \& Conagin, A. (2001) - Viabilidade de uso do delineamento composto central. Acta Scientiarum, vol. 23, n. 6, p. 1537-1546.

Nacata, G.; Andrade, R.A.D.; Jasper, S.P. \& Prata, R.S. (2014) - Propagação de variedades de caramboleira por estaquia herbácea. Revista Brasileira de Fruticultura, vol. 36, n. 1, p. 248-253. http://dx.doi.org/10.1590/01002945-237/13

Nicoloso, F.T.; Lazzari, M. \& Fortunato, R.P. (1999) - Propagação vegetativa de Platanus acerifolia Ait: (II) Efeito da aplicação de zinco, boro e ácido indolbutírico no enraizamento de estacas. Ciência Rural, vol. 29, n. 3, p. 487-492. http://dx.doi.org/10.1590/S0103-84781999000300018 
Paula, L.A.; Boliani, A.C.; Souza Corrêa, L. \& Celoto, M.I.B. (2007) - Efeito do ácido indolbutírico e raizon no enraizamento de estacas herbáceas e lenhosas de umbuzeiro. Acta Scientiarum Agronomy, vol. 29, n. 3, p. 411-414. http://dx.doi.org/10.4025/actasciagron.v29i3.468

Peña, M.L.; Gubert, C.; Tagliani, M.C.; Bueno, P.M.C. \& Biasi, L.A. (2012) - Doses e formas de aplicação do ácido indolbutírico na propagação por estaquia dos mirtileiros cvs. Flórida e Clímax. Semina: Ciências Agrárias, vol. 33, n. 1, p. 57-64. http://dx.doi.org/10.5433/1679-0359.2012v33n1p57

Rios, S.E.M.C.; Pereira, L.S.; Santos, T.C. \& Souza, V.G.R. (2012) - Doses de acido indol butírico comprimento e época de coleta de estacas na propagação de umbuzeiro. Revista Caatinga, vol. 25, n. 1, p. 52-57.

Sabião, R.R.; Silva, A.D.C.C.D.; Martins, A.B.G. \& Cardoso, E.R. (2011) - Enraizamento de estacas de Passiflora nitida submetidas a diferentes doses de ácido indolbutírico (AIB). Revista Brasileira de Fruticultura, vol. 33, n. sp., p. 654-657. http://dx.doi.org/10.1590/S0100-29452011000500091

Santos, M.B.; Cardoso, R.L.; Fonseca, A.A.D.O.; Nascimento Conceição, M. \& Neto, A.D.A. (2013) - Avaliação físico-química e microbiológica de polpa de frutos de umbu-cajazeira, por métodos combinados. Magistra, vol. 25, n. 1, p. 7-13.

Silva, F.V.G.; Silva, S.M.; Silva, G.C.; Mendonça, R.M.N.; Alves, R.E. \& Dantas, A.L. (2012) - Bioactive compounds and antioxidant activity in fruits of clone and ungrafted genotypes of yellow mombin tree. Ciência Tecnologia de Alimentos, vol. 32, n. 4, p. 685-691. http://dx.doi.org/10.1590/S0101-20612012005000101

Souza, R.R.; Cavalcante, M.Z.B.; Lima, M.P.D.; Alixandre, T.F. \& Nascimento, R.T. (2015) - Propagação vegetativa de hibisco com diferentes tipos de estacas e concentrações de ácido indolbutírico. Comunicata Scientiae, vol. 6, n. 3, p. 291-296. http://dx.doi.org/10.14295/CS.v6i3.679

Tosta, M.S.; Oliveira, C.V.F.; Freitas, R.M.O.; Porto, V.C.N.; Nogueira, N.W. \& Tosta, P.A.F. (2012) - Ácido indolbutírico na propagação vegetativa de umbu-cajazeira (Spondias sp.). Semina: Ciências Agrárias, vol. 33, sup. 1, p. 2727-2740. http://dx.doi.org/10.5433/1679-0359.2012v33Supl1p2727

Véras, M.L.M.; Mendonça, R.M.N.; Ramires, C.M.C.; Silva, S.M. \& Pereira, W.E. (2017) - Efeito de ethephon e ácido indolbutírico na propagação de cajazeira via estaquia. Pesquisa Agropecuária Tropical, vol. 47, n. 4, p. 416-423.

Viana, E.D.S.; Mamede, M.E.D.O.; Reis, R.C.; Carvalho, L.D.D. \& Fonseca, M.D. (2015) - Development and evaluation of dietetic and conventional jam of umbu-caja (Spondias sp.). Revista Brasileira de Fruticultura, vol. 37, n. 3, p. 708-717. http://dx.doi.org/10.1590/0100-2945-018/14

Wendling, I.; Trueman, S.J. \& Xavier, A. (2014) - Maturation and related aspects in clonal forestry - part II: reinvigoration, rejuvenation and juvenility maintenance. New Forests, vol. 45, n. 4, p. 473-486. http://dx.doi. org/10.1007/s11056-014-9415-y

Yamamoto, L.Y.; Koyama, R.; Borges, W.F.S.; Antunes, L.E.C.; Assis, A.M. \& Roberto, S.R. (2013) - Substratos no enraizamento de estacas herbáceas de amora-preta Xavante. Ciência Rural, vol. 43, n. 1, p. 15-20.

Zem, L.M.; Zuffellato-Ribas, K.C.; Radomski, M.I. \& Koehler, H.S. (2015) - Enraizamento de estacas semilenhosas de cataia coletadas em quatro estações. Ciência Rural, vol. 45, n. 10, p. 1815-1818. http://dx.doi. org/10.1590/0103-8478cr20140534 